\title{
Modelling of the fuel injection of medium speed marine diesel engines
}

The article presents the stages of fuel injection modeling of the four-stroke marine diesel engines as a set of functional blocks the of the fuel waves flow. The elaborated model includes the values of changing pressures in the combustion chamber and the course of changes of the pressure in spaces of the injection pump, injection pipe and the injector. Linear and local losses, as well as the conditions for the functioning were taken into account in stages of the fuel flow.

The influence of different values of the engine load on the pressure course of the in individual spaces of injection apparatus and in the engine cylinder during the working cycle depending on the crank angle of rotation of the crankshaft have been simulated. The mathematical relationships were selected and the structural and experimental data are used, allowing the calculation of the parameters of interest for the simulated process.

Key words: marine engines, injection subsystem, injection course, modeling

\section{Introduction}

Modeling is the first step in the formal description of problems related to functioning analysis and the synthesis of research objects. Modeling allows you to approximate the principles of organization, as well as how the object works, resulting in information about modelled system. It also allows you to reduce the cost and time research.

The model is a tool that allows you to describe the object and its behavior in different conditions of the external and internal using relations on a set of input and output sizes. The purpose of modeling is to obtain reliable mathematical model that allows you to trace the ways of behavior of the test object under the influence of extorting factors.

The essence of the simulation research of the fuel injection process is the development of models that allow understanding the physical phenomena that determine the quality of the injection. Conducting experiments on a real object in the laboratory is expensive and time consuming, and sometimes impossible, especially for large marine engines, and exploitation examinations are hampered on account of staying ships in seas and oceans where conditions of investigations are dependent from transient transport situations.

The utility and ecological parameters are largely determined by the combustion rate, characterized by the process of heat release and pressure changes. The combustion process efficiency is mainly conditioned by the quality of fuel-air mixture preparation. Among many factors influencing these processes, and connected with the injection system, the following ones should be specified [4]:

- beginning, duration and rate of injection fuel dose;

- pressure course and speed of fuel injection;

- location of fuel jet in the combustion chamber.

The validity of applying models is determined by the degree of conformity of the model with the real system of the fuel injection. Applying models is determined by the degree of conformity of the model with the real system of the fuel injection.

\section{State of knowledge in the scope of the modeling of the fuel injection process}

One of the factors determining macrostructure and microstructure in injection molding is the fuel distribution in time called injection $[4,15,17]$. Due to the short duration of injection (in milliseconds), its course occurs in closed spaces at high pressures and interactions of one phase with another. These processes have not been fully studied.

Basic equations of dynamics of fuel were formulated for the general model with applying three main principles of behaviour mechanics [5, 10, 17]:

- mass,

- momentum and the angular momentum,

- energy.

In the computational model of the pumping subsystem additional factors were taken into account $[5,10,15]$ :

- changes in supply pressure as the result of the hydraulic impacts occurring during the pressing;

- elastic deformation of the injection pump drive;

- changes of the coefficient of fuel flow through throttling holes, depending on the hole cross section;

- injection subsystem leakage;

- movement resistance of the discharge valve head;

- damping the retaining surfaces of the head at the socket and the bumper;

- the elasticity of valve head and valve seat.

In previous models of the process of fuel injection simplifying assumptions were made, where it is possible to notice the dominance of applying finite element methods, geometric models, complicated mathematical descriptions and relations applied in practice.

The shortening of the optimum solutions obtainment time can be achieved by the formulated of mathematical models of injection subsystems of feed system and calculation of the parameters of interest in the numerical simulation methods. Many simulations of the diesel engine fuel injection subsystem are carried out in order to find the optimum fuel injection parameters [9]. The characteristics and the finite difference method have been applied to solve the governing equations. According to the author [7] recent studies show that finite difference method is superior to the method of characteristics concerning computation time and nonlinearity.

Methods proposed in literature of modeling of the injection process require selection at the preliminary stage and experimental verification. 
The development of engines nowadays is conditioned mostly by a implementation of the stricter ecological standards, but for obvious reasons also fuel economy and movement parameters are taken into consideration.

\section{Methodology of examinations}

\subsection{Object of examinations}

The object of the study was a four-stroke diesel marine engine the drive Sulzer company of the drive generator with conventional fuel injection subsystem. Each cylinder is supplied the diesel oil by its individual fuel injection pump.

Up to now, research has been done on two types of engines, which limits the randomness of the results. The modeling object is the classic injection subsystem of Sulzer's four-stroke marine engine. In the so far commonly used conventional fuel systems the course of injection process is controlled in the very narrow range. On marine vessels the accumulator systems are still not implemented, there are major problems with the injection apparatus, and the costs of fuel were dominating in the profitability of ships. As regulation parameters there are the fuel dose and the change in the injection angle.

This system consists of the following elements (Fig. 1):

- the injection pump with the adjustment of the productivity with the pumping overflow valve,

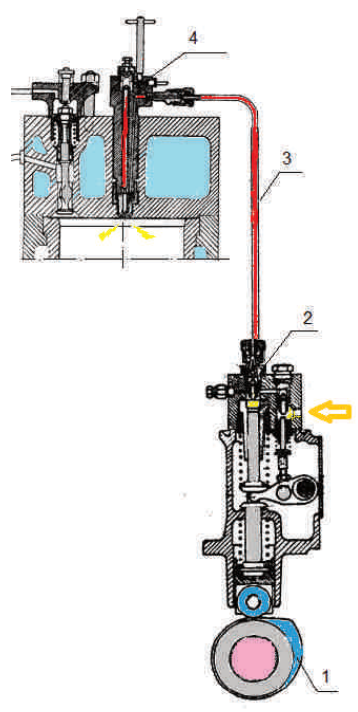

Fig. 1. Scheme of the injection subsystem of the four-stroke internal combustion engine: 1 - fuel cam, 2 - delivery valve, 3 - injection line, 4 injector valve

Table 1. The main specifications of test injection subsystem

\begin{tabular}{|l|l|l|}
\hline On. & Characteristics & Technical specification \\
\hline 1 & Cylinder bore & $220 \mathrm{~mm}$ \\
\hline 2 & Piston stroke & $320 \mathrm{~mm}$ \\
\hline 3 & Rotational speed (constant) & $500 \mathrm{rpm}$ \\
\hline 4 & Maximum engine power & $220 \mathrm{~kW}$ \\
\hline 5 & Pump type & $\begin{array}{l}\text { With the regulation of dose on } \\
\text { pumping }\end{array}$ \\
\hline 6 & Plunger diameter & $17 \mathrm{~mm}$ \\
\hline 7 & Opening fuel valve pressure & $215 \mathrm{bar}$ \\
\hline 8 & Fuel pipe inner diameter & $2 \mathrm{~mm}$ \\
\hline 9 & Nozzle hole number & 6 \\
\hline 10 & Nozzle hole diameter & $0.3 \mathrm{~mm}$ \\
\hline 11 & Needle lift (maximal) & 0.4 \\
\hline 12 & Nozzle hole angle & $130 \mathrm{deg}$ \\
\hline
\end{tabular}

- of the injection conduit,

- the injector with the multi-hole nozzle.

Each cylinder is powered with diesel oil using individual injection pump. Characteristic data of the investigated engine and elements of the injection subsystem was placed in Table 1.

\subsection{Method of experimental investigations}

For experimental studies he was used resistance sensors of the course of pressures in a combustion chamber. He also mounted a resistance pressure sensor on the discharge of the injection pump, and signals were visualized and analyzed using a portable computer (Fig. 2). In addition, recorded the top dead center. The analysis of these signals was run by time and crank angle of crankshaft domain using DaqView program [13]. Relative load the team was being carried out with the water resistor in the period from 0 to $100 \%$ with relative load the team was being carried out with the water resistor in the period from 0 up to the $100 \%$ with stepping every $25 \%$.

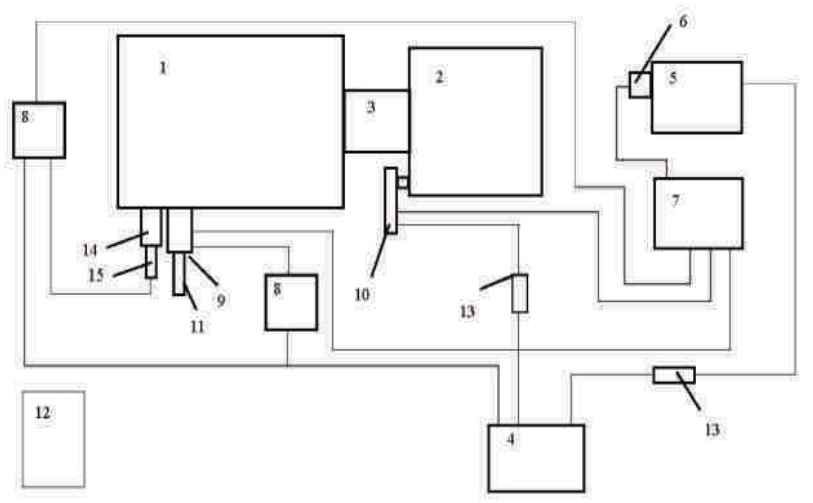

Fig. 2. Measuring circuit of investigations: 1 -internal combustion engine, 2 - generator, 3 - shaft with clutch the permanent clutch, 4 - power supply, 5 - portable computer, 6 - measuring card analog-digital, 8 - signal amplifier, 9 - injection pump, indicators valves, 10 - crankshaft position sensor, 11 - pressure sensor in the injection pump, pressure sensor, 12 weather monitoring device, 13 - power supply 14-cylinder indicator valve, 15 - pressure sensor in the combustion chamber

On Figure 3 the course of the pressure indicates in the combustion chamber for one cylinder at burdening the $0 \%$. Some results of experimental studies were used for calculations in the model, as: fuel feed pressure of injection pump, charge air pressure, course in-cylinder pressure of engine.

\subsection{Modeling method}

A physical model is a theoretical concept mapping processes and phenomena that occur in the real object. The degree of simplification of the actual object arises from modeling conditions, as the state of the art and the need and implementation conditions.

Two kinds of hardware models were builded. The model of the post of the injection subsystem was one of them apart from the engine with real elements. The second type is a virtual physical model which imitates elements of the comprehensive subsystem injection, enabling to take chosen phenomena into account (Fig. 4). Elements of the model are geometric models elaborated based on limited design data, protected by the producer, supplemented with geometrical measurements of new and exploited parts $[6,14]$. The 
functional model includes sequences of closed cycles, where the end of one circulation is the beginning of the next circulation of the engine. The shape of the fuel cam was determined based on geometrical measurements of the real cam (Fig. 5).

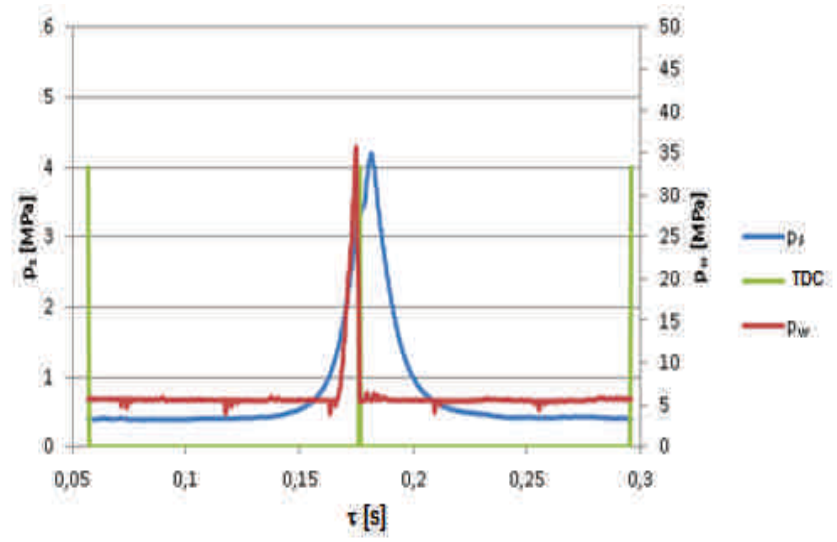

Fig. 3. Course of the pressure in a combustion chamber and the injection pump of the cylinder for one cycle at engine load of the $0 \%$ : $\mathrm{p}_{\mathrm{s}}$ - pressure course in the combustion chamber, TDC - top dead centre, $\mathrm{p}_{\mathrm{w}}$ - pressure in the injection pump

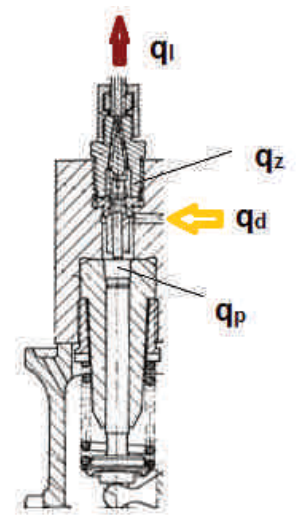

Fig. 4. Structural subsystem of the injection pump: $q_{d}-$ stream of fuel reaching the injection pump,: $\mathrm{q}_{\mathrm{t}}-$ stream of fuel pumped by the crowd, $\mathrm{q}_{\mathrm{z}}$ - stream of fuel flowing through the delivery valve, $\mathrm{q}_{1}-$ stream of fuel flowing into the injection pipe

On Figure 6 an edge geometric model drawn up for the purposes of this work with the SolidWorks computer program was introduced. Similarly a geometry of the wire of the injection pump and the injection pipe was determined [14].

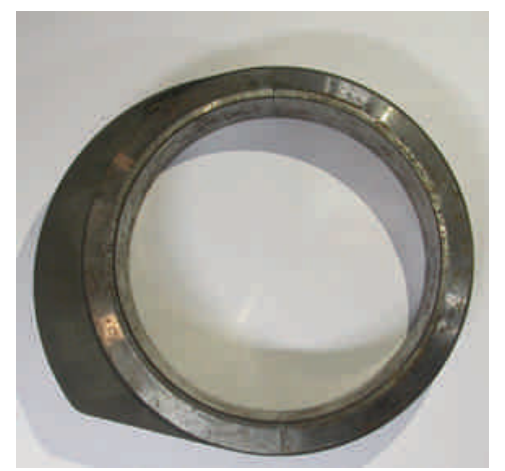

Fig. 5. The image the fuel cam of the inspected engine

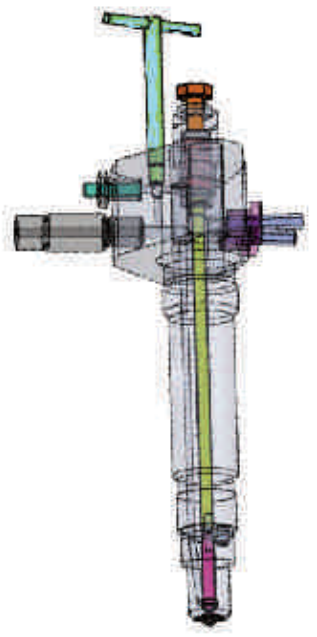

Fig. 6. Edge geometric model of the injector of the investigated engine [11]

In the article the mathematical simulation of the fuel injection process runs in the single-cylinder injection pump is presented. The verification of the model was done in correlation with the results obtained on a real engine. An analysis of presented results of the mathematical simulation gives good reason for ascertains that results correctly reproduce course of characteristics.

During the modelling of the process of the fuel injection the following computer programs were used: AutoCAD, Microsoft Excel, Matlab, COMSOL Multiphysics, SolidWorks.

In this paper, it was decided to take into account the effect of the course of the pressure in the engine cylinder on the course of the fuel injection which not all authors took into account, and of changes of medium parameters. The calculations include the influence of pressure and temperature on the parameters of the pumped fuel such: density, kinematic viscosity and modulus of elasticity.

\section{Modeling results}

\subsection{Introductory remarks}

Basic fuel dynamics equations were formulated for the general model using the basic principles of behavior mechanics [3, 17]:

- mass,

- momentum and the angular momentum,

- energy.

Mathematical model of injection subsystem includes the description of its geometrical and physical features as well as characteristic mathematical relations describing dynamics of hydraulic phenomena and structural elements. The design of the injection subsystem and the different assumptions for the individual components of this subsystem necessitate dividing it into three construction units and the corresponding three groups of equations describing the processes occurring. Due to the limited volume of the article, only examples of injection pumps were given.

An attempt to solve the problem more quickly and more cheaply was made with numerical way using data from experimental studies. It sought to bring the results of the modeling results to the experimental studies which was 
checked by comparison. The work of the injection pump is controlled by the cam, being on the camshaft. Motion of pump piston depends on the lifts of fuel cam and camshaft position $h_{p}=h_{p}\left(\alpha_{w}\right)$. The change of transferring the piston pump in individual time intervals allows to the determine speed values of the lifts of the plunger in characteristic points:

$$
\mathrm{v}_{\mathrm{t}}=\frac{\mathrm{dh}_{\mathrm{p}}}{\mathrm{d} \tau}
$$

The lift course of the piston of the injection pump and the speed of the piston in the fuel forcing phase, for the investigated engine, were described in Fig. 7. These values were appointed based on the outline of the fuel cam on the camshaft.

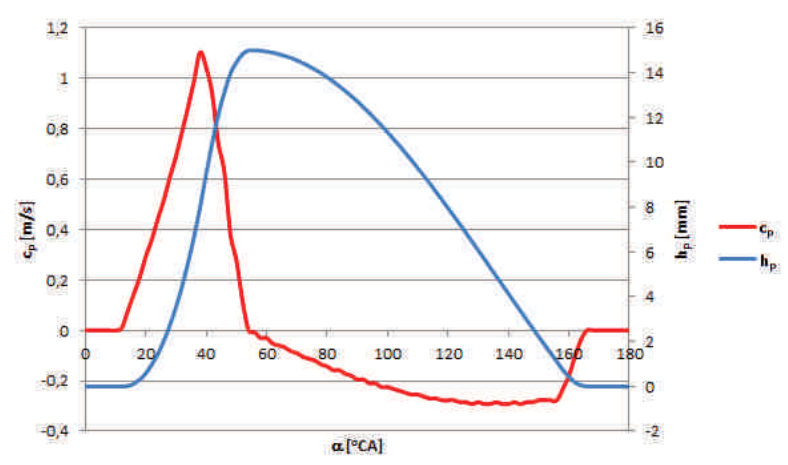

Fig. 7. Lift and velocity of plunger of the injection pump

Fuel injection pump with the valve with strain relief $h_{r}$ working stroke is preceded by stroke $h_{0}$ arising from needs to supplement the volume of fuel injection subsystem, released by relief stroke calculated with the formula:

$$
\mathrm{h}_{\mathrm{o}}=\frac{4 \mathrm{~V}_{\mathrm{o}}}{\pi \mathrm{d}_{\mathrm{p}}^{2}}
$$

Working stroke is calculated with the formula $h_{r}$ :

$$
\mathrm{h}_{\mathrm{r}}=\frac{4 \mathrm{~V}_{\mathrm{p}}}{\pi \mathrm{d}_{\mathrm{p}}^{2}}
$$

\subsection{Modelling of hydrodynamic phenomena in the pressing subsystem of the injection pump}

The following types of equations were used to describe these phenomena. Fuel flow continuity equation for individual spaces of the pumping subsystem:

$$
\frac{\mathrm{V}}{\mathrm{E}} \frac{\mathrm{dp}}{\mathrm{d} \tau}=\Sigma \mathrm{q}
$$

where: $\mathrm{V}$ - volume of the chamber taken into consideration of the pumping subsystem, E - modulus of elasticity of fuel, $\mathrm{p}$ - pressure of fuel in the considered space, $\Sigma q-$ sum of inlet and outlet streams of fuel to and from the space.

Equation of motion of delivery valve, being the balance of the dynamic forces acting on the valve in the form of:

$$
\mathrm{m} \frac{\mathrm{d}^{2} \mathrm{~h}}{\mathrm{~d} \tau^{2}}=\sum \mathrm{P}
$$

where: $\mathrm{m}$ - mass of the moving element, $\Sigma \mathrm{P}-$ the sum of the forces acting on the delivery valve.

Equation describing the stream of the fuel flow $q$ through considered holes with cross sections A:

$$
q=\mu A \sqrt{\frac{2}{\rho}\left(p_{1}-p_{2}\right)}
$$

where: $\mu$ - flow coefficient, $\mathrm{A}$ - the geometric cross section to flow, $\rho-$ fuel density, $\mathrm{p}_{1}-\mathrm{p}_{2}-$ pressure difference on both sides of the hole.

Equation of swelling pressure in the inlet or outlet of the flow hole as the result of the change of the volume stream $q$ flowing through the opening [17]:

$$
d p= \pm \operatorname{sign}(q) \frac{\rho a}{A} d q
$$

where: sign - plus or minus, a - speed of sound in fuel.

Continuity equations for the space above the injection pump plunger can be written as [5]:

$$
\begin{aligned}
& A_{p}\left[c_{p}-w_{p w}(\alpha) A_{p} \frac{d p_{p}}{d \tau}\right]=w_{s 1} \mu_{o} A_{o} j \sqrt{\frac{2}{\rho}\left|p_{p}-p_{d}\right|}-A_{z c} \frac{d h_{z}}{d \tau} \\
& -\mathrm{w}_{\mathrm{s} 2} \mu_{\mathrm{z}} \mathrm{A}_{\mathrm{z}} \sqrt{\frac{2}{\rho}\left|\mathrm{p}_{\mathrm{p}}-\mathrm{p}_{1}\right|}-\mathrm{A}_{\mathrm{z}} \frac{\mathrm{dh}_{\mathrm{g}}}{\mathrm{d} \tau}+\frac{\mathrm{V}_{\mathrm{p}}}{\mathrm{E}} \frac{\mathrm{dp} \mathrm{p}_{\mathrm{p}}}{\mathrm{d} \tau}+\mathrm{q}_{\mathrm{u}}
\end{aligned}
$$

where: $A_{p}$ - active cross section of the pump piston, $c_{p}-$ the actual speed of the injection pump piston, with regard the elastic deformations, $\mathrm{w}_{\mathrm{pw}}(\alpha)$ - camshaft deformability

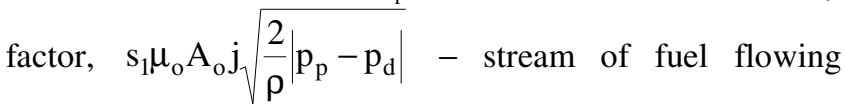
through the intake hole in the injection pump, $\mathrm{j}$ - nozzle hole number, $p_{p}-p_{d}-$ difference pressures between the chamber in the injection pump cylinder and the inlet space, $\mathrm{q}_{\mathrm{u}}$ - stream of leakages of fuel as the result of the leakiness of the pumping element, $\mathrm{w}_{\mathrm{s} 1}-$ control indicator equal 1 or 1 depending on the sign of the pressure difference $p_{p}-p_{d}$, $\mathrm{w}_{\mathrm{s} 2} \mu_{\mathrm{z}} \mathrm{A}_{\mathrm{z}} \sqrt{\frac{2}{\rho}\left|\mathrm{p}_{\mathrm{p}}-\mathrm{p}_{1}\right|}$ - stream of fuel flowing through the discharge valve, $A_{z}\left(h_{g}\right)$ - the cross-section between the socket and the head of discharge valve, $p_{p}-p_{1}-$ differential pressure between chamber in the cylinder of the injection pump and fuel injection pipe, $\mathrm{w}_{\mathrm{s} 2}-$ the control indicator equal is 1 or -1 depending the sign of differential pressure, $p_{p}-p_{1}, c_{z}-$ velocity of the inlet fuel stream, $\frac{V_{p}}{E} \frac{d p_{p}}{d \tau}-$ stream of fuel accumulated in the $V_{p}$ volume of the cylinder as the result of the change of the prevailing pressure.

Boundary conditions in pumping subsystem of injection pump determine the equation of head of discharge valve [5]:

$$
\mathrm{m}_{\mathrm{z}} \frac{\mathrm{d}^{2} \mathrm{~h}_{\mathrm{z}}}{\mathrm{d} \tau^{2}}=\mathrm{A}_{\mathrm{z}}\left(\mathrm{p}_{\mathrm{p}}-\mathrm{p}_{1}\right)-\mathrm{w}_{\text {or }} \frac{\mathrm{dh}_{\mathrm{z}}}{\mathrm{d} \tau}-\left(\mathrm{P}_{\mathrm{z}}+\mathrm{k}_{\mathrm{z}} \mathrm{h}_{\mathrm{z}}\right)
$$

where: $m_{z} \frac{d^{2} h_{z}}{d \tau^{2}}$ - inertia force working on the moving elements of the valve (mass of head and one third mass of 
the spring), $A_{z}-$ cross-section of discharge valve, $k_{z}-$ spring constant, $\mathrm{P}_{\mathrm{z}}$ - force of preliminary of the valve spring tension, $\mathrm{w}_{\mathrm{or}}-$ motion resistance coefficient.

Continuity equation for the flow for chambers in discharge connector of the injection pump is possible to calculate according to the pattern:

$$
\frac{\mathrm{V}_{2}}{\mathrm{E}} \frac{\mathrm{dp_{ \textrm {k } }}}{\mathrm{dt}}=\mathrm{w}_{\mathrm{s} 2} \mu_{\mathrm{z}} \mathrm{A}_{\mathrm{z}} \sqrt{\frac{2}{\rho}\left|\mathrm{p}_{\mathrm{p}}-\mathrm{p}_{\mathrm{k}}\right|}+\mathrm{A}_{\mathrm{z}} \frac{\mathrm{dh}_{\mathrm{g}}}{\mathrm{d} \tau}-\mathrm{A}_{\mathrm{k}} \mathrm{c}_{\mathrm{k}}
$$

where: $A_{k} c_{k}$ - fuel stream flowing from the pumping subsystem of the injection pump to the chamber of injection pump with the cross-section area and injection speed $c_{k}$, $\frac{V_{2}}{E} \frac{d p_{k}}{d t}$ - fuel stream accumulated in the volume $V_{k}$ capacity of the connector tube of injection pump the result of the move of the valve head pumping as the result of the pressures change.

Residual pressure values $\mathrm{p}_{\mathrm{sc}}$ are possible to measure or approximately can be calculated according to the formula:

$$
\mathrm{p}_{\mathrm{sc}}=\mathrm{p}_{\mathrm{ow}}-\Delta \mathrm{p}=\mathrm{p}_{\mathrm{ow}}-\mathrm{E} \frac{\mathrm{V}_{\mathrm{hp}}-\mathrm{V}_{\mathrm{o}}}{\mathrm{V}_{\mathrm{hp}}}
$$

where: $p_{o w}$ - injector opening pressure, $\Delta p$ - pressure drop caused by the opening of the injector nozzle, $\mathrm{E}$ - modulus of fuel elasticity, $\mathrm{V}_{\mathrm{hp}}$ - volume of the high pressure part of the system injection subsystem, $\mathrm{V}_{\mathrm{o}}$ - relief volume.

In the papers geometric models were swapped over based on design requirements and measurements of real elements of injection apparatus [6, 14]. In the paper [12] a functional model drawn up was elaborated for the different type of the medium-speed marine engine.

\subsection{Regard into account the changeability of parameters of fuel}

The fuel is a perfectly springy liquid and defers to the Hooke's law, which determines the change of the length of the element triggered with change of the pressure [5]:

$$
\varepsilon_{\mathrm{c}}=\frac{\mathrm{dp}}{\mathrm{E}}=-\frac{\mathrm{dx}}{\mathrm{x}}=-\frac{\mathrm{dV}}{\mathrm{V}}
$$

where: $\varepsilon_{\mathrm{c}}$ - unit change in length of the element of the liquid, $\mathrm{dx}$ - change the length of the fuel element, $\mathrm{dV}$ change of the volume of the fuel element.

Assuming that the mass of the element due to pressure increase will not change, it can be written as:

$$
d V=d\left(\frac{m}{\rho}\right)=-\frac{m}{\rho^{2}} d \rho
$$

where $\rho$ is density of the fuel.

The speed of the propagation of the pressure wave $a_{p, t}$ in the injection subsystem is determined by the elasticity of $\mathrm{E}$ fuel, the elasticity of material of the injection pipe according to the formula:

$$
a_{p, t}=\frac{1}{\sqrt{\rho_{p, t}\left(\frac{1}{E_{p, t}}+\frac{1}{E_{s}} \frac{d_{w l}}{s_{1}}\right)}}
$$

$\mathrm{E}_{\mathrm{p}, \mathrm{t}}-$ modulus of elasticity of fuel at pressure $\mathrm{p}$ and temperature $t, E_{s}$ - modulus of elasticity of the material injection, $\mathrm{d}_{\mathrm{wl}}-$ internal diameter of injection pipes, $\mathrm{s}_{1}-$ injection pipe wall thickness.

Sebyła based on experimental studies formulated the equation on $\mathrm{E}_{\mathrm{p}, \mathrm{t}}$ in the form [5]:

$$
\mathrm{E}_{\mathrm{p}, \mathrm{t}}=\mathrm{E}_{\mathrm{ot}}+9.375 \mathrm{p}-0.00625 \mathrm{p}^{2}
$$

where: $\mathrm{E}_{\mathrm{ot}}$ - modulus of elasticity at the atmospheric pressure and the given temperature. On the Fig. 8. the course of the modulus of elasticity of fuel was shows for one circulation of the engine changing depending on the pressure and the temperature.

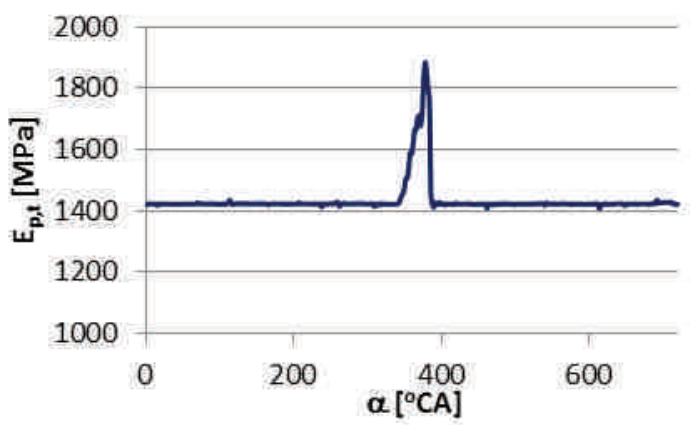

Fig. 8. The course of the modulus of elasticity of fuel was shows for one circulation of the engine

The influence of inlet liquid fuel temperature and pressure on direct-injection diesel engines can be significant. The primary fuel temperature effects on the injection parameters come from the fuel elasticity modulus of elasticity and the density with the fuel viscosity less significant as the injector subsystem flow is usually in a turbulent region [2].

Increasing the fuel temperature by $1 \mathrm{~K}$ in the $\mathrm{x}$ place caused by the pressure increase of $10 \mathrm{MPa}$ [5], which can be written as:

$$
\mathrm{t}_{\mathrm{px}}=\mathrm{t}_{\mathrm{d}}+\left(\mathrm{p}_{\mathrm{px}}-\mathrm{p}_{\mathrm{o}}\right) / 10
$$

where: $t_{p x}$ - pressure of fuel in the $x$ place, $t_{d}$ - temperature of the inlet of fuel, $p_{p x}$ - pressure of fuel in the $x$ place, $p_{o}-$ ambient pressure.

The density of fuel is being changed with the change of temperature and pressures. Individual authors are giving different relations, and according to Dowa and the Finn determine the pattern [5]:

$$
\rho_{\mathrm{p}, \mathrm{t}}=\rho_{\mathrm{o}}\left(1+\mathrm{mp}-\mathrm{np}^{2}\right)
$$

where: $\mathrm{m}, \mathrm{n}-$ the factors dependent on the temperature, $\rho$ - density of fuel in current terms, $\mathrm{p}$ - pressure of fuel.

It is hard at deriving equations describing the movement of fuel in the wire to include constant changes of the pressure, flows of fuel, but adoption of their constant value is an significant error $[4,14]$. On Fig. 9 the course of the density of fuel was showed within one circulation.

Dynamic viscosity varies with temperature and fuel pressure, and it was calculated according to the relation:

$$
\eta_{\mathrm{p}, \mathrm{t}}=\eta_{20}\left(\frac{20}{\mathrm{t}}\right)^{\mathrm{w}} \mathrm{e}^{\mathrm{w}_{\mathrm{p}}}
$$


where: $\eta_{20}-$ absolute viscosity of fuel at the atmospheric pressure and the environmental temperature, absolute viscosity of fuel at the atmospheric, $\mathrm{w}_{\mathrm{t}}$ - temperature coefficient, $\mathrm{w}_{\mathrm{p}}-$ pressure coefficient.

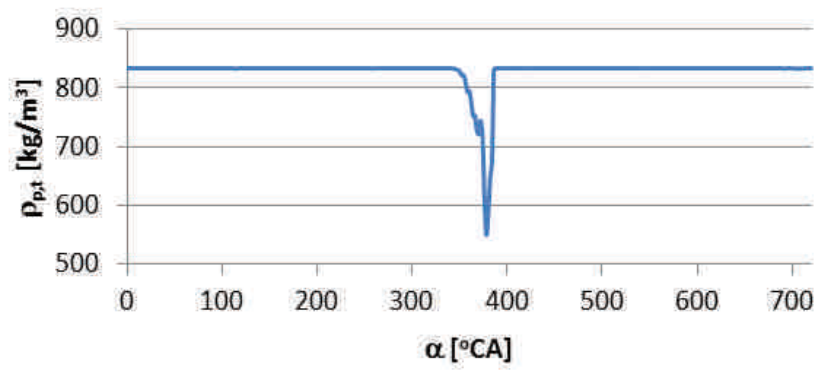

Fig. 9. Change of the fuel density of $\rho_{p, t}$ depending on the pressure and the temperature

The kinematic viscosity can be calculated from the relation:

$$
v_{\mathrm{p}, \mathrm{t}}=\frac{\eta_{\mathrm{p}, \mathrm{t}}}{\rho_{\mathrm{p}, \mathrm{t}}}
$$

or from the empirical model [5].

\subsection{Calculating losses and coefficients}

During the model calculations a number of losses and simplifications were assumed. The stream of leaked fuel from injection pump can be calculated with the formula [8]:

$$
\mathrm{q}_{\mathrm{pp}}=\frac{\mathrm{p}_{\mathrm{t}} \mathrm{w}_{\mathrm{sc}} \delta^{3}}{12 \eta_{\mathrm{p}, \mathrm{t}}}
$$

$\mathrm{w}_{\mathrm{sc}}$ - factor in determining the ratio of the width to the length of slot, $\delta$ - radial clearance between piston and sleeve.

Radial clearance between the plunger and the cylinder fuel injection pump and nozzle body and needle for was determined for operated state by the geometric measurements $[6,14]$. The flow coefficient depends on the substantial amount of factors as: shapes of holes, radii of the edge, state of the surface, geometrical dimensions, Reynolds number, parameters of flowing fuel $[5,6]$. Yomaoka and others gave the formula for empirical coefficient of discharge valve in the form [18]:

$$
\mu_{\mathrm{z}}=0.26 \operatorname{tg}^{-1}\left[(4 \mathrm{p}+500)\left(\mathrm{h}_{\mathrm{z}}-\frac{0.0144}{\sqrt[3]{\mathrm{p}}}\right)\right]+0.15
$$

where: $h_{z}$ lift of the delivery valve.

In the forces acting on the moving parts of delivery valves and injector valves should be taken of the strength of the opposition's force of movement which results from the viscosity of fuel filling room up on the circumference of the element. This force is proportional to the lateral surface of the element and the gradient of the fuel speed:

$$
\mathrm{P}=\eta_{\mathrm{p}, \mathrm{t}} \pi \mathrm{d}_{\mathrm{m}} 1_{\mathrm{e}} \frac{\mathrm{dc}}{\mathrm{dn}}
$$

where: $d_{m}-$ diameter of the movable element, $1_{e}-$ the length of the element movable, $\mathrm{n}$ - normal coordinate to the direction of movement of the movable element.

$$
\mathrm{P}=\eta_{\mathrm{p}, \mathrm{t}} \frac{\pi \mathrm{d}_{\mathrm{m}} \mathrm{l}_{\mathrm{e}}}{\delta} \mathrm{c}=\mathrm{w}_{\text {or }} \frac{\mathrm{dx}}{\mathrm{d} \tau}
$$

where: $\mathrm{w}_{\text {or }}=\eta \frac{\pi \mathrm{d}_{\mathrm{m}} \mathrm{l}_{\mathrm{e}}}{\delta}$ coefficient of resistance of the move of the element of valve head, $\delta$ - layer thickness of fuel between the movable element and the wall of the body.

The friction losses in rectilinear or gently bent pipes are calculated from the formula [3]:

$$
\mathrm{h}_{\mathrm{stl}}=\frac{\Delta \mathrm{p}}{\gamma}=\lambda_{1} \frac{\mathrm{lc}^{2}}{2 \mathrm{gd}_{1}}, \lambda=\lambda\left(\operatorname{Re}, \mathrm{r} / \mathrm{d}_{1}\right)
$$

where: $\Delta \mathrm{p}-$ drop of the pressure, $\gamma$ - specific gravity of liquid, $\lambda_{1}-$ coefficient of linear losses on friction, $r / d_{1}-$ relative roughness of the internal wall of the pipe, $\mathrm{Re}-$ Reynolds number.

The line loss factor is calculated depending on the type of flow [3]:

- for flow in the Reynolds number range 3000 to 80000 :

$$
\lambda_{1}=\frac{0.316}{\operatorname{Re}^{0.25}}
$$

- for larger number of Reynolds number 100000 to 1600 000 according to the formula Schilera-Herman:

$$
\lambda_{1}=0.0054+0.396 \mathrm{Re}^{-0.3}
$$

At flows under pressure local losses associated with sudden changes of the diameter and direction which the viscosity of liquid is causing are appearing in wires and they depend on the Reynolds number. The height of the local losses is expressed by the formula:

$$
\mathrm{h}_{\mathrm{stl}}=\xi_{1} \frac{\mathrm{c}^{2}}{2 \mathrm{~g}}
$$

where: $\zeta$ - dissipation local factor, g - gravitational acceleration.

The following local loss cases were accounted in the injection subsystem of the tested engine [1]: knee and inflection of the injection line, sudden constriction at the outlet of the injection pump and entry into the spray opening, inlet with rounded edges, tees, etc.

\subsection{Comparison of the calculated and measured results}

Due to the limited volume of this article, only the examples of the injection pump were give. The relation of the set of functional elements is shown in Figure 1.

The stream of fuel pumped by individual holes of the injection subsystem can be transformed in order to appoint the pressure course of fuel in spaces of the injection subsystem. The pressure sensor in the experimental study was placed at the point where the pressure in the injection pump cylinder was measured. The formula for the fuel stream flowing through the delivery valve is of the form (equation 8): 


$$
\mathrm{q}_{\mathrm{z}}=\mathrm{w}_{\mathrm{s} 2} \mu_{\mathrm{z}} \mathrm{A}_{\mathrm{z}} \sqrt{\frac{2}{\rho}\left|\mathrm{p}_{\mathrm{p}}-\mathrm{p}_{1}\right|}
$$

The fuel stream pumped by the plunger of the injection pump depends on the diameter $d_{p}$ of the piston of the pump and the pumping speed of $c_{p}$ and perhaps to be calculated as:

$$
\mathrm{q}_{\mathrm{p}}=\frac{\pi \mathrm{d}_{\mathrm{p}}^{2} \mathrm{c}_{\mathrm{p}}}{4}
$$

This stream should be reduced by the losses shown in chap. 4.4. Fig. 10 illustrates exemplary of the pressure

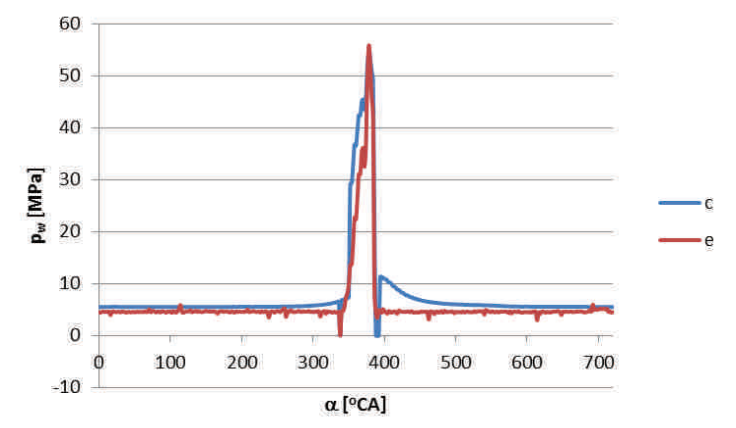

Fig. 10. The pressure course of in the injection pump measured in experimental studies (e) and calculated (c) for the $100 \%$ of the engine load

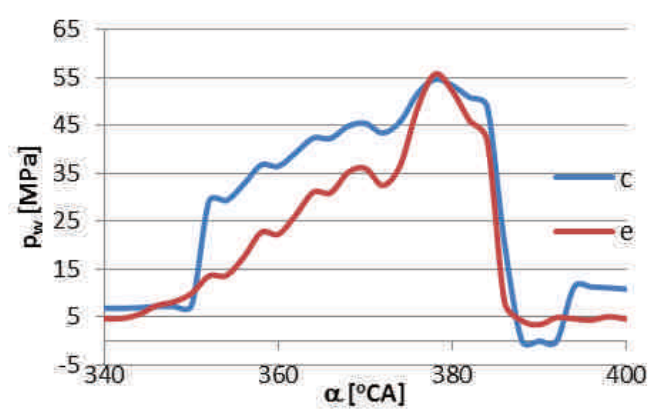

Fig. 11. Fragment of pressure courses in the injection pump measured in experimental studies (e) and calculated (c) for the $100 \%$ of the engine load

course of fuel pumped in the injection pump, appointed based on calculations and from experimental investigated and at the rotation speed of camshaft at $250 \mathrm{rpm}$. The figure shows that the waveforms are similar.

For a better comparison of the courses studied, the part of the waveforms was shown where the fuel injection occurred (Fig. 11). The figure shows that the maximum values of the waveforms are the same, while the values of the experimental pressure are generally lower. At the end of fuel injection, there are also differences in residual pressure.

\section{Conclusions}

The mathematical model for numerical simulation of injection processes was developed and verified by experiments under several operating load regimes. Estimated courses of the pressure in chambers of the injection subsystem are similar to courses occurring in the experimental road in laboratory tests of the real engine. Presented model requires correcting to the purpose increasing of pressure course in injection subsystem calculated to experimental.

Elaborated geometric and functional model of injector subsystem and used mathematical relations, enable to conduct the wide scope of research of the fuel injection process.

The input variables can be: fuel setting, fuel inlet pressure of injection pump, opening pressure of the injector, engine parameters and operating conditions of the injector. Features of the technical state can be design features of the elements of injection subsystem, changed according to the value of design solutions and processes of wear and damages.

Currently operated the conventional injection systems may be also optimized thanks to the modelling from the point of view of useful engine parameters and diagnosis methods, and especially under the angle of ecological requirements which must to fulfil. The elaborated model out makes possible the quick simulation of this process in different variants, without the construction of prototypes or time-consuming experimental investigations.

\section{Acknowledgements}

This research outcome has been achieved under the research project Ecological and economic aspects of the operation of selected elements of marine power systems No. 1/S/IESO/2014 financed from a subsidy of the Ministry of Science and Higher Education for statutory activities.

\section{Nomenclature}

a speed of sound propagation in fuel

$A_{p} \quad$ area of cross-section of the plunger

$\mathrm{A}_{\mathrm{z}} \quad$ area of cross-section of the in-valve chamber

c velocity

$d_{p} \quad$ piston diameter

$\mathrm{E}$ modulus of fuel elasticity

$\mathrm{H}_{\mathrm{p}} \quad$ position of the piston of injection pump

1 pipe length

m mass

$\mathrm{m}_{\mathrm{z}} \quad$ mass of moving elements in the valve

$\mathrm{p}$ pressure

$\mathrm{P}$ force

$\mathrm{p}_{\mathrm{p}} \quad$ pressure in chamber of pumping section $\mathrm{p}_{\mathrm{z}} \quad$ pressure in chamber of the delivery valve

q streams of fuel flowing into and out of space

$\mathrm{t}$ temperature

V volume

$\mathrm{V}_{\mathrm{p}} \quad$ volume of fuel pressed by the injection pump

$\mathrm{x} \quad$ length of the liquid element

$\alpha \quad$ crank angle

$\lambda$ dissipation factor linear to the friction

$\mu \quad$ flow coefficient

$\eta \quad$ instantaneous dynamic viscosity coefficient of fuel

$\rho \quad$ density of the fuel

$\tau \quad$ time 


\section{Bibliography}

[1] BUKOWSKI, J. Mechanika płynów, PWN, Warszawa 1975.

[2] CHEN, G. Study of fuel temperature effects on fuel injection, combustion, and emissions of direct-injection diesel engines. Trans. ASME. J. Eng. Gas Turbines and Power. 2009, 2, 022802/1-022802/8.

[3] CIAŁKOWSKI, M. Mechanika płynów, Wyd. Politechniki Poznańskiej, Poznań 2000.

[4] CYGAN, S., SZYMAŃSKI J. Podstawowe problemy doboru aparatury wtryskowej silników wysokoprężnych. WKiE, Warszawa 1979.

[5] FALKOWSKI, H., HAUSER, G., JANISZEWSKI, T., JASKUŁA A. Układy wtryskowe silników wysokoprężnych. Modelowanie. WKit, Warszawa 1989, cz. 2.

[6] JERMAK, C., MAJCHROWSKI, R., MONIETA, J. The application of geometric measurement and analysis of images for mapping geometric model marine engine injection equipment. Combustion Engines. 2011, 146(3), 71-72.

[7] KEGL, B. Numerical analysis of injection characteristics using biodiesel fuel, Energy \& Fuel. 2006, 22(2), $2377-$ 2378.

[8] KIIJÄRVI, J. Diesel fuel injection system simulation. Publications of the Internal Combustion Engine Laboratory Helsinki University of Technology Teknillisen korkeakoulun polttomoottori laboratorion julkaisuja Espoo 2003.

[9] KOLADE, B., BOGHOSIAN, M., REDDY P., GALLAGHER S. Development of a general-purpose, thermalhydraulic software and its application to fuel injection systems. SAE Technical Paper. 2003, 2003-01-0702.

[10] LEONARSKI, P. Opracowanie modeli diagnostycznych wybranego okrętowego silnika spalinowego. Praca dyplo-

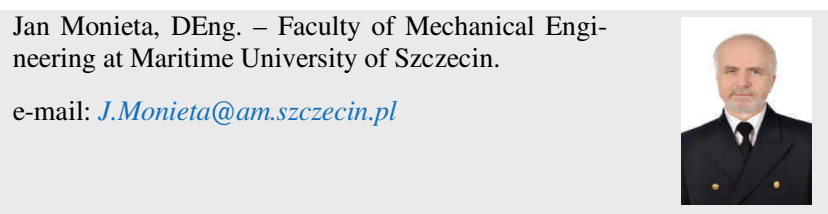

mowa inżynierska. Akademia Morska w Szczecinie, Wydział Mechaniczny, Szczecin 2016.

[11] LEJDA, K., USTRZYCKI, A. Modelling of injection characteristic with in-line type injection pump in diesel engines. III International Scientific-Technical Conference EXPLODIESEL \& GAS TURBINE'03, Gdańsk - Międzyzdroje Lund. 5-9.05.2003, 369-374.

[12] MONIETA, J. Functional model of injector of mediumspeed marine diesel engine. Journal of KONES 2007 Powetrain and Transport. 2007, 14(3), 423-428.

[13] MONIETA, J. The application in-cylinder pressure course in different domains for diagnostics of medium speed marine diesel engines in operation conditions. Combustion Engines. 2013, 154(3), 153-160.

[14] MONIETA, J. Zastosowanie pomiarów geometrycznych i analizy obrazów do odwzorowania modelu geometrycznego pomp wtryskowych silnika okrętowego. XXXIII Symposium of Power Plant, SYMSO 2012, Gdynia 2012, 37, cd. 1-8.

[15] PIASECZNY, L., KAFAR, I. Simulation researches of evaporation and combustion of a single drop of fuel in CI engine. Journal of Kones. Combustion Engines. 2001, 8(12), 312-319.

[16] SABAU, A., BARHALESCU, M.L., OANTA, E. Modeling of high-pressure fuel injection systems. Annals of DAAAM for 2012 \& Proceedings of the 23rd International DAAAM Symposium, Vienna, Austria, 2012, 1019-1022.

[17] SOBIESZCZAŃSKI, M. Modelowanie procesów zasilania w silnikach spalinowych. WKiE, Warszawa 2000.

[18] YOMAOKA, K., SAITO, A., OKAZAKI, M. Analysis or by-pas control type fuel injection system for small diesel engine by digital computer. Bulletin of the JSME. 1972, 82. 